\title{
Article
}

\section{The Influence of Eating at Home on Dietary Diversity and Airway Inflammation in Portuguese School-Aged Children}

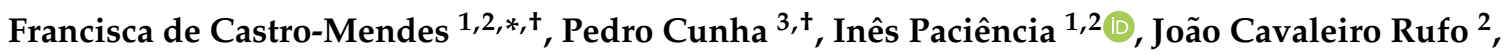 \\ Mariana Farraia ${ }^{1,2} \mathbb{D}^{-}$, Diana Silva ${ }^{1,4}$, Patrícia Padrão ${ }^{2,3} \mathbb{D}^{-}$, Luís Delgado ${ }^{1,3,4} \mathbb{D}^{\text {, André Moreira }}{ }^{1,2,3,4}$ \\ and Pedro Moreira ${ }^{2,3}$ (D)
}

Citation: de Castro-Mendes, F.; Cunha, P.; Paciência, I.; Cavaleiro Rufo, J.; Farraia, M.; Silva, D.; Padrão, P.; Delgado, L.; Moreira, A.; Moreira, P. The Influence of Eating at Home on Dietary Diversity and Airway Inflammation in Portuguese School-Aged Children. Int. J. Environ Res. Public Health 2021, 18, 2646. https://doi.org/10.3390/ ijerph18052646

Academic Editor: Paul B. Tchounwou

Received: 30 January 2021

Accepted: 26 February 2021

Published: 5 March 2021

Publisher's Note: MDPI stays neutral with regard to jurisdictional claims in published maps and institutional affiliations.

Copyright: (c) 2021 by the authors. Licensee MDPI, Basel, Switzerland. This article is an open access article distributed under the terms and conditions of the Creative Commons Attribution (CC BY) license (https:/ / creativecommons.org/licenses/by/ $4.0 /)$.
1 Serviço de Imunologia Básica e Clínica, Departamento de Patologia, Faculdade de Medicina da Universidade do Porto, 4200-319 Porto, Portugal; inespaciencia@gmail.com (I.P.); mariana.farraia@gmail.com (M.F.); disolha@gmail.com (D.S.); ldelgado@med.up.pt (L.D.); andremoreira@med.up.pt (A.M.)

2 EPIUnit-Instituto de Saúde Pública, Universidade do Porto, 4050-091 Porto, Portugal; jcrufo@gmail.com (J.C.R.); patriciapadrao@fcna.up.pt (P.P.); pedromoreira@fcna.up.pt (P.M.)

3 Faculdade de Ciências da Nutrição e Alimentação da Universidade do Porto, 4150-177 Porto, Portugal; pedrocunha27@hotmail.com

4 Serviço de Imunoalergologia, Centro Hospitalar São João, 4200-319 Porto, Portugal

* Correspondence: francisca_castromendes@hotmail.com

+ These authors contributed equally to this work.

Abstract: Considering the negative impact of a lack of dietary diversity on children's nutritional status, we aimed to describe dietary variety according to eating at home frequency and assessed its association with respiratory outcomes in school-aged children. This cross-sectional study included 590 children (49\% girls) aged 7 to 12 years from 20 public schools located in city of Porto, Portugal. Daily frequency of eating at home groups were calculated and dietary diversity was calculated using a 10-food group score from a $24 \mathrm{~h}$ recall questionnaire. Spirometry and exhaled nitric oxide levels ( $\mathrm{eNO} ;<35$ and $\geq 35 \mathrm{ppb}$ ) were assessed. The comparison of diet diversity according to the groups was performed by ANOVA and ANCOVA. The association between dietary diversity and respiratory outcomes was examined using regression models. In multivariate analysis, children in the highest group of eating at home episodes ( $\geq 4$ occasions) obtained the lowest dietary diversity mean score, while the lowest group $(<2)$ had the highest mean score ( $p$-value 0.026$)$. After adjustment for confounders, higher diet diversity ( $\geq 5$ food groups) significantly decreased the odds of having an eNO $\geq 35$. Diet diversity might decrease the chance of airway inflammation among children. However, having more eating episodes at home could be a barrier to a more diverse diet.

Keywords: airway inflammation; children; diet; dietary quality; dietary diversity; eating at home; eNO

\section{Introduction}

In parallel with the increasing incidence of allergic diseases, there has been a change in diet, which is framed in the western lifestyle pattern [1]. This western dietary pattern is characterized by a high intake of processed meats, refined grains, and sugary foods, and low intake of plant-based foods [2], which might compromise the supply of important dietary components with anti-oxidant and anti-inflammatory properties involved in protection against asthma development [3]. Among these dietary components, the lower intake of fruits and vegetables, which are important sources of dietary fibre, micronutrients, and phytochemicals that participate in antioxidant and anti-inflammatory metabolic activities, seems to be a potential contributor for the risk of asthma development [4]. However, dietary components are not consumed alone and may exhibit synergic effects within the food and between foods when consumed together [5], and asthma is an heterogeneous disease that results from several risk factors [6].

Considering the negative impact of the lack of dietary diversity on child nutritional status [7], indicators of diet variety are attractive as a measure of nutritional adequacy [8,9]. 
Furthermore, diet diversity may be relatively simple to measure, and could expand the limitation of assessing the effects of diets from single dietary components $[8,9]$, while considering the interactions of the matrixes from a variety of foods on health $[10,11]$. Several observational studies have evaluated the dietary quality through the assessment of the Mediterranean diet, which is characterized not only by a higher consumption of fruits, vegetables, and wholegrain cereals, but also by a greater variety of these foods [12]. Higher adherence to the Mediterranean diet has been associated with less occurrence of asthma [13], less asthma symptoms [14,15], and asthma control [16]. On the other hand, in adults, higher healthy eating dietary scores, including the Alternate Healthy Eating Index 2010, were associated with a lower asthma symptom score [17] and asthma symptoms improvement in longitudinal analysis with a 7-year follow-up period [18]. In children, a higher diet quality score decreased the odds of having asthma [19].

In accordance with the western lifestyle, eating episodes outside home also increased, which might be an explanation for a poorer diet quality [20]. It was found that children who regularly consumed takeaway meals at home had an higher daily energy intake [21]. However, eating outside the home is not always related with poorer eating quality, and the results are mixed. Results from a Portuguese birth cohort showed that preschool children having more meals in preschools consumed more vegetables, fruits, cereals, and fish and presented a better dietary adequacy [22], and other studies have also documented a higher nutritional quality of school meals compared with meals from home [23,24]. More recently, Calixto Andrade et al. evaluated the association between eating out and ultraprocessed food consumption, founding a positive association between the consumption of ultra-processed foods and eating out of home, when compared to individuals eating at home [25]. Similarly, in a representative sample from UK children, those following a pattern of eating out of home had a higher consumption of ultra-processed foods compared to those following a pattern related to eating at school with friends [26].

Children spend most of their day out of home, so it is plausible that dietary diversity and nutritional intake might be impacted according the foods obtained at home and outside the home, particularly at school [23], consequently affecting diseases such as asthma and its related outcomes. One of the measures used to assess diet diversity in children is the Minimum Dietary Diversity for Women (MDD-W) of reproductive age assessment, which was originally developed to evaluate diet diversity through micronutrient adequacy at the population-level from non-pregnant women of reproductive age [27]. It was also shown that a higher MDD-W was modestly associated with a lower risk of ischemic heart disease [28]. In children aged 4 to 8 years, higher MDD-W was associated with overall micronutrient adequacy [29]. However, there are no previous studies evaluating the differences of MDD-W score between eating locations and its association with respiratory and allergic outcomes. Therefore, we aimed to describe diet diversity according to eating at home frequency, and to assess the association between diet diversity and asthma, lung function, and airway inflammation as well as respiratory and asthma symptoms in schoolaged children.

\section{Materials and Methods}

\subsection{Study Design and Participants}

This cross-sectional study included 590 participants aged 7 to 12 years, who attended the 3rd and 4th grades at 71 classrooms from 20 public schools located in the city of Porto, Portugal [30]. From the 1602 children who were invited to participate, those who did not provide informed consent $(n=686)$, refused to perform clinical procedures $(n=58)$, or had incomplete nutritional data were not included $(n=268)$. Significant differences between included and not included participants were found for forced expiratory volume in the first second (FEV1) and forced expiratory flow middle portion of forced vital capacity (FEF25-75) reversibility and positive bronchodilation $(p<0.05$, Table S1). 
Written consent was obtained from each child's legal guardian or parent. The Ethics Committee of the University Hospital São João approved the study. Every procedure was carried out in accordance with Helsinki Declaration.

\subsection{Diet and Minimum Dietary Diversity for Women (MDD-W) at Reproductive Age Assessment}

The participants were asked about their diet through a single $24 \mathrm{~h}$ recall questionnaire. According to a standard procedure, this questionnaire allowed the detailed collection of data from all the foods and beverages consumed in the previous $24 \mathrm{~h}$, including the quantity, respective food brands and cooking methods [31]. These data were recorded per eating occasions that included information about the place and time of consumption. Eating occasions were defined based on any occasion when a food or beverage is consumed with at least $30 \mathrm{~min}$ of interval and providing a minimum of $50 \mathrm{kcal}$ of energy [32]. The eating occasions performed outside of home included all the meals that were not eaten at home, including other homes, such as those of friends, grandparents, or other relatives, at schools, restaurants, or cafes, "on the go" (e.g., car/bus or stress) and leisure places (e.g., sports club). Daily frequency of eating at home groups were defined based on the number of eating occasions performed at home: G1, less $(<)$ than 2; G2, equal to 2; G3, equal to 3; and G4, more $(\geq)$ than 4 . Total energy intake (kcal) was assessed through the software Food Processor $^{\circledR}$ (ESHA Research, Salem, OR, USA), which encompasses databases of Portuguese nutritional food-composition and was used as a continuous variable.

Dietary diversity was assessed through the Minimum Dietary Diversity for Women (MDD-W) at reproductive age assessment [33]. Ten food groups were defined according the guidelines for MDD-W in which ingredients in mixed dishes or unmixed foods and beverages consumed in quantities $\geq 15 \mathrm{~g}$ were matched [33]: grains, white roots and tubers, and plantains ("starchy staples", including all types of breads, pasta or potatoes); pulses (beans, peas, and lentils); nuts and seeds (mostly tree nuts but, groundnut as well as nut and seed "butters"); dairy (almost all liquid and solid dairy products from cows, goats, buffalo, sheep or camels); meat, poultry, and fish (meats, organ meats, poultry and other birds and fresh and dried fish and seafood/shellfish); eggs; dark green leafy vegetables (medium green leaves, including Chinese cabbage, romaine and bibb lettuce, broccoli or spinach along with darker greens); other vitamin A-rich fruits and vegetables (namely ripe mango and papaya, passion fruit, apricot and several types of melons, as well as, carrot, pumpkin and deep yellow- or orange-fleshed squash); other vegetables (all the vegetables not considered as dark green leafy vegetables or as other vitamin A-rich vegetables, namely tomato or cucumber); and other fruits (all the fruits not included as vitamin A-rich fruits, namely sweet white bananas, apple, or kiwi). Each consumed group received 1 point and were counted to create the MDD-W diversity score, which range between 0 and 10. A dichotomous indicator was also calculated based on whether or not participants have consumed at least five out of ten defined foods [33]. We also considered other food groups of concern as suggested in this score [33], namely "other oils and fats" (e.g., butter, margarine and "shortening"), "savory and fried snacks" (e.g., doughnuts/fried dough), "sweets" (e.g., candy, chocolates and cakes), "sugar-sweetened beverages" (e.g., "juice drinks", chocolate drinks and sweet tea), and "red and/or processed meat". Although these groups were not included to calculate the MDD-W, we counted them to create the "concerning food score".

\subsection{Current Respiratory and Asthma Symptoms Assessment}

The legal guardian answered a questionnaire based on the International Study of Asthma and Allergies in Childhood (ISAAC), which posed questions about social, demographic, and behavioral information and included questions about respiratory/allergic health and respiratory symptoms [34].

Asthma symptoms in the previous year, which includes wheezing and cough symptoms, were defined based on a positive answer to the question "did your child have wheezing or whistling in the chest in the past 12 months?", and "did your child suffer 
coughing at night in the last 12 months?" or "did your child suffer coughing more than three months in the last year?".

Current respiratory symptoms were defined based on a positive answer to the question "during the past 3 months, has your child had any of the following symptoms?": "irritative cough" and "breathing difficulties".

\subsection{Spirometry and Asthma Assessment}

Spirometry with bronchodilation was performed. Lung function was evaluated before and $15 \mathrm{~min}$ after the inhalation of $400 \mu \mathrm{g}$ of salbutamol following the official American Thoracic Society/ The European Respiratory Society (ATS/ERS)guidelines [35]. Positive bronchodilation (+BD) was defined by at least a $12 \%$ and over $200 \mathrm{~mL}$ increase in FEV1. Self-report of asthma diagnosed by a physician was defined based on a positive answer to the question "has your child ever been diagnosed with asthma by a physician?".

As previously described [36], three different definitions of asthma were considered: (i) ever: self-reported medical diagnosis; (ii) medical diagnosis with asthma symptoms or +BD-self-reported medical diagnosis with reported symptoms (wheezing, dyspnea or dry cough) occurring in the past 12 months or +BD; and (iii) medical diagnosis and under asthma treatment-self-reported medical diagnosis and currently under anti-asthma medication.

\subsection{Fractional Exhaled Nitric Oxide (eNO) Assessment}

Fractional exhaled nitric oxide was measured through a NObreath analyzer (Bedfont Scientific Ltd., Rochester, Kent, UK) to assess airway inflammation. The results were expressed as parts per billion (ppb) and stratified according to the official ATS guidelines for children [37], which were dichotomized according to the cut point equal or above $(\geq)$ $35 \mathrm{ppb}$ as increased levels of eNO.

\subsection{Other Covariates}

Allergic sensitization was evaluated through skin-prick-tests (SPT), which were performed on children's forearms using a QuickTestTM (Panatrex Inc., Placentia, California, USA applicator), which included house dust mite, mix of weeds (Urtica dioica, Plantago lanceolate and Artemisia vulgaris), mix of grasses (Agrostis stolonifera, Anthoxathum odoratum, Dactylis glomerata, Lolium perenne, Arrhenatherium elatius, Festuca rubra, Poa pratensis, Holcus lanatus, Phleum pratense, Secale cereal), cat dander, dog dander, and Alternaria alternata, negative control (extracts dilutant), and a positive control consisting of histamine at $10 \mathrm{mg} / \mathrm{mL}$ (Hall Allergy, Netherlands). Results were read after $15 \mathrm{~min}$. Atopy was defined based on a positive SPT (wheal $\geq 3 \mathrm{~mm}$ diameter) to at least one of the allergens.

Self-reported medical diagnosis of food allergy (FA) diagnosis was defined based on a positive answer to the following two questions "has your child ever been allergic to any food?" and "was the allergy diagnosed by the doctor?".

Weight was measured using a digital scale (Tanita ${ }^{\mathrm{TM}}$ BC-418 Segmental Body Analyzer) and recorded in kilograms $(\mathrm{kg})$. Height was assessed with a portable stadiometer and recorded in centimeters $(\mathrm{cm})$. Weight and height were used to calculate body mass index (BMI), computed as $\mathrm{kg}$ per square meters $\left(\mathrm{kg} / \mathrm{m}^{2}\right)$, and classified according to age- and sex-specific percentiles defined by the US Centers for Disease Control and Prevention (CDC) [38].

Parental' education level is presented as the number of successfully completed years of formal schooling of the parent at the higher education level and categorized into three classes: $\leq 9$ years; $\geq 10$ years and $\leq 12$ years; and $>12$ years. Maternal smoking during pregnancy was obtained from a positive answer to the question "did the mother smoke during pregnancy?". Exposure to tobacco at home was defined by a positive answer to the question "is your child exposed to tobacco smoke at home?". Child nutritional supplementation was assessed through a positive question "has your child taken nutritional supplements (vitamins/minerals) in the past year?". 


\subsection{Statistical Analyses}

Continuous variables are expressed as median (25th-75th percentile), while categorical variables are presented as percentages. To determine differences between groups of daily frequency of eating at home, the Kruskal-Wallis test for continuous variables and the chisquared test for categorical variables were performed. To describe the differences between daily frequency of eating at home groups, we calculated the number and percentage of children consuming foods from each food group.

The comparison of mean MDD-W score according to groups of daily frequency of eating at home was performed using ANOVA. ANCOVA was used to adjust for potential confounders: age, sex, atopy, self-reported medical diagnosis of FA, BMI categories, parental education, child nutritional supplementation, number of eating occasions, and energy intake. Bonferroni correction for multiple comparisons was applied.

Linear regression models $(\beta)$ were used to analyze the association between lung function and the MDD-W indicator. Similarly, logistic regression models (odds ratio; $\mathrm{OR})$ were used to investigate the association between diet diversity and the increased levels of eNO, +BD, and asthma definitions, as well as asthma and current respiratory symptoms. These regressions were adjusted in three consecutive models as follows: crude model—main effect; model 1—age, sex, atopy, self-reported medical diagnosis of FA, BMI categories, parental education, maternal smoking during pregnancy, tobacco smoke at home, child nutritional supplementation, and daily frequency of eating at home groups; and model 2-model 1, concerning food score and total energy intake. Asthma defined by medical diagnosis with asthma symptoms or +BD was additionally considered in the linear regression model. The interaction of groups of daily frequency of eating at home groups on the association with each outcome was examined by a product term added into fully adjusted models. No significant interactions were detected ( $p$-value $>0.05$ )

A 0.05 level of significance and $95 \%$ confidence interval (CI) were considered. SPSS statistical package software v26.0 (IBM, Armonk, NY, USA) was used to carry out all the analyses.

\section{Results}

The proportion of participants eating 5 or more food groups (G1 $=80.30 \%$; $\mathrm{G} 2=79.40$; $\mathrm{G} 3=67.40$; and G4 $=58.60, p$-value $=0.001$, Table 1$)$ and the total energy $(\mathrm{kcal})$ intake $(\mathrm{G} 1=2067.80 ; \mathrm{G} 2=2228.00 ; \mathrm{G} 3=2246.84 ;$ and G4 $=2465.77, p$-value $<0.001)$ was significantly different among daily frequency of eating at home groups.

All participants consumed starchy staple foods, and nearly all consumed dairy, meat, poultry, and fish, other vegetables, and other fruits (Table 2). Children who consumed $>4$ eating occasions at home had the lowest consumption of other vegetables ( $Q 1=90.20 \%$, $\mathrm{Q} 2=84.80 \%, \mathrm{Q} 3=76.30 \%$, and $\mathrm{Q} 4=58.60 \%$; $p$-value $=0.001$, Table 2 ) and other fruits $(\mathrm{Q} 1=82.90 \%, \mathrm{Q} 2=82.40 \%, \mathrm{Q} 3=75.60 \%$, and Q4 $=56.90 \% ; p$-value $<0.001$, Table 2$)$. These children had also the highest consumption of sweets $(\mathrm{Q} 1=66.84 \%, \mathrm{Q} 2=79.41 \%$, $\mathrm{Q} 3=73.33 \%$, and $\mathrm{Q} 4=84.48 \%$; $p$-value $=0.009$ ). 
Table 1. Characteristics of the participants according to daily frequency of eating at home groups.

\begin{tabular}{|c|c|c|c|c|c|c|}
\hline Participants Characteristics & $\begin{array}{c}\mathrm{G} 1 \\
n=193(32.70)\end{array}$ & $\begin{array}{c}\mathrm{G} 2 \\
n=204(34.60)\end{array}$ & $\begin{array}{c}\mathrm{G} 3 \\
n=135(22.90)\end{array}$ & $\begin{array}{c}\mathrm{G} 4 \\
n=58(9.80)\end{array}$ & $\begin{array}{c}\text { Total, } \\
n=590\end{array}$ & $p$-Value \\
\hline Age (years) & $9.00(8.00-9.00)$ & $9.00(8.00-9.00)$ & $9.00(8.00-9.00)$ & $9.00(8.00-9.00)$ & $9.00(8.00-9.00)$ & 0.967 \\
\hline Female sex, $n(\%)$ & $100(51.80)$ & $91(44.60)$ & $66(48.90)$ & $32(55.20)$ & $289(49.0)$ & 0.381 \\
\hline Atopy ${ }^{1}, n(\%)$ & $60(31.40)$ & $76(37.40)$ & $49(36.80)$ & $19(32.80)$ & $204(34.90)$ & 0.586 \\
\hline Self-reported medical diagnosis of FA, $n(\%)$ & $13(6.70)$ & $13(6.40)$ & $5(3.70)$ & $5(8.60)$ & $36(6.10)$ & 0.540 \\
\hline BMI categories ${ }^{2}, n(\%)$ & & & & & & 0.346 \\
\hline Normal weight & $129(66.80)$ & $151(74.00)$ & $95(70.40)$ & $42(72.40)$ & $417(70.7)$ & \\
\hline Overweight & $34(17.60)$ & $23(11.30)$ & $19(14.10)$ & $5(8.60)$ & $81(13.70)$ & \\
\hline Obese & $23(11.90)$ & $18(8.80)$ & $17(12.60)$ & $6(10.3)$ & $64(10.80)$ & \\
\hline Parental education ${ }^{3}, n(\%)$ & & & & & & 0.620 \\
\hline$\leq 9$ & $48(33.80)$ & $60(36.10)$ & $40(36.00)$ & $21(44.70)$ & $169(36.30)$ & \\
\hline$\geq 10$ and $\leq 12$ & $39(27.50)$ & $52(31.30)$ & $38(34.20)$ & $13(27.70)$ & $142(30.50)$ & \\
\hline$>12$ & $55(38.70)$ & $54(32.50)$ & $33(29.70)$ & $13(27.70)$ & $155(33.30)$ & \\
\hline Tobacco at home, $n(\%)$ & $56(34.10)$ & $74(43.00)$ & $40(34.80)$ & $21(41.20)$ & $191(38.0)$ & 0.308 \\
\hline Child nutritional supplementation, $n(\%)$ & $22(13.30)$ & $26(14.20)$ & $18(14.90)$ & $13(25.00)$ & $79(15.10)$ & 0.210 \\
\hline Increased levels of eNO ${ }^{4}, n(\%)$ & $17(8.90)$ & $32(15.80)$ & $18(13.50)$ & $8(13.80)$ & $75(12.80)$ & 0.230 \\
\hline Positive bronchodilation ${ }^{5}, n(\%)$ & $13(6.70)$ & $6(2.90)$ & $9(6.70)$ & $4(6.90)$ & $32(5.40)$ & 0.290 \\
\hline \multicolumn{7}{|l|}{ Asthma definitions, $n(\%)$} \\
\hline Ever & $11(6.00)$ & $21(10.70)$ & $5(3.80)$ & $4(7.10)$ & $41(7.20)$ & 0.097 \\
\hline Medical diagnosis with asthma symptoms or $+\mathrm{BD}$ & $19(9.80)$ & $20(9.80)$ & $9(6.70)$ & $6(10.30)$ & $54(9.20)$ & 0.725 \\
\hline Medical diagnosis and under asthma treatment & $9(4.70)$ & $16(7.80)$ & $4(3.00)$ & $4(6.90)$ & $33(5.60)$ & 0.238 \\
\hline Lung function & & & & & & \\
\hline
\end{tabular}


Table 1. Cont.

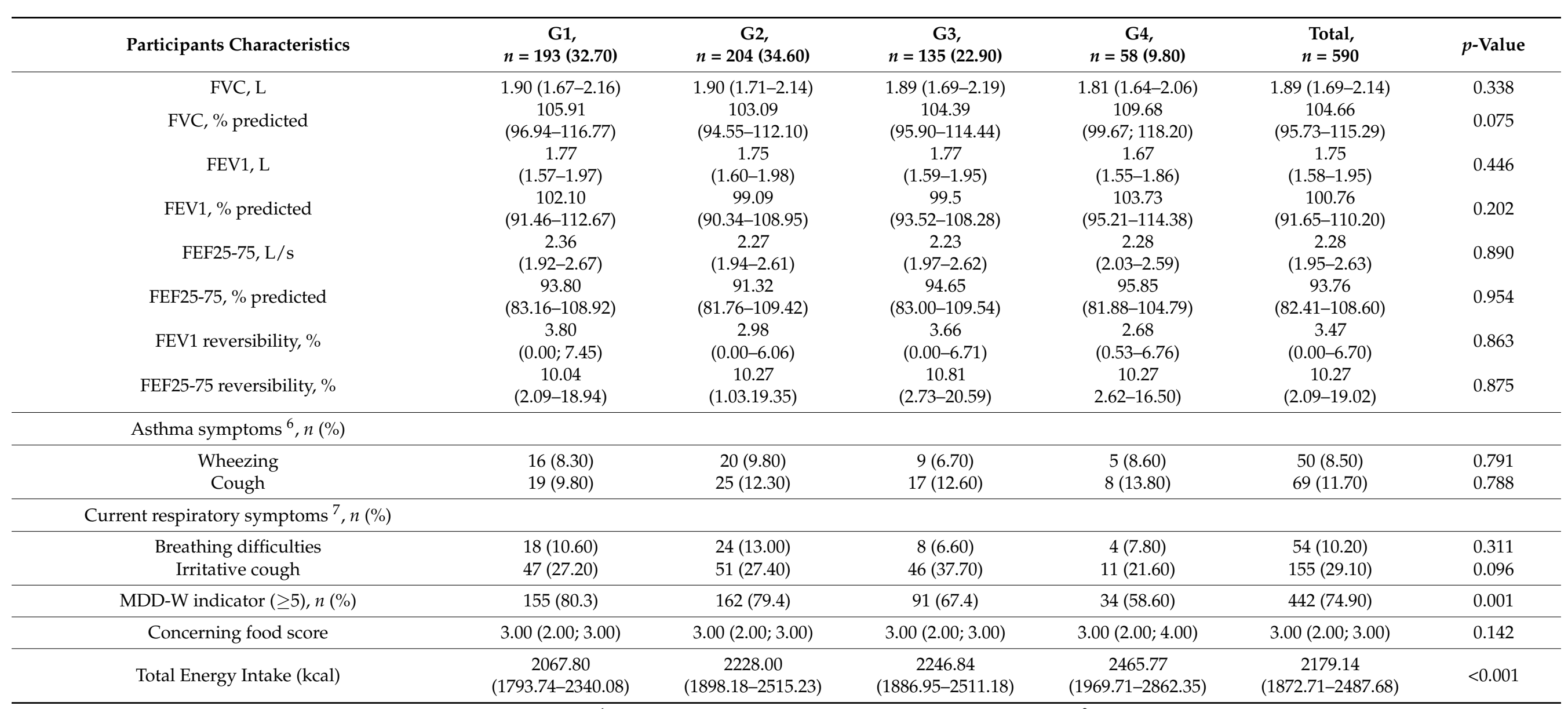

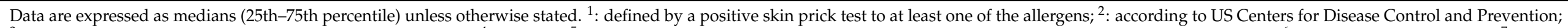

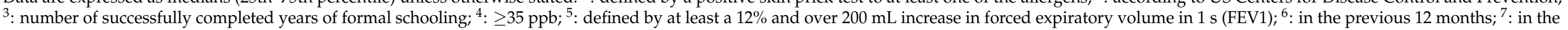

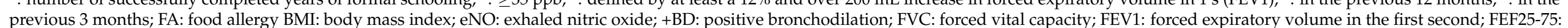

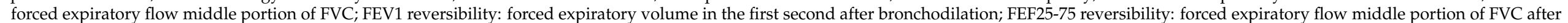
bronchodilation. MDD-W: The Minimum Dietary Diversity for Women of reproductive age assessment. 
Table 2. Consumption of food groups from the MDD-W according to groups of daily frequency of eating at home.

\begin{tabular}{|c|c|c|c|c|c|c|}
\hline Food Groups from MDD-W & G1, $n=193(32.70)$ & $\mathrm{G} 2, n=204(34.60)$ & G3, $n=135$ (22.90) & G4, $n=58(9.80)$ & Total, $n=590$ & $p$-Value \\
\hline Grains, white roots and tubers, and plantains & $193(100)$ & $204(100)$ & $135(100)$ & $58(100)$ & $590(100)$ & - \\
\hline Pulses (beans, peas, and lentils) & $51(26.40)$ & $53(26.00)$ & $34(25.30)$ & $10(17.20)$ & $148(25.10)$ & 0.538 \\
\hline Nuts and seeds & $3(1.60)$ & $6(2.90)$ & $0(0.00)$ & $1(1.70)$ & $10(1.70)$ & 0.235 \\
\hline Dairy & $148(76.70)$ & $162(79.40)$ & $110(81.50)$ & $53(91.40)$ & $473(80.20)$ & 0.099 \\
\hline Meat, poultry, and fish & $188(97.40)$ & $200(98.00)$ & $132(97.80)$ & $55(94.80)$ & $575(97.50)$ & 0.582 \\
\hline Eggs & $18(9.30)$ & $16(7.80)$ & $10(7.40)$ & $4(6.90)$ & $48(8.10)$ & 0.895 \\
\hline Dark green leafy vegetables & $36(18.70)$ & $46(22.50)$ & $29(21.50)$ & $12(20.70)$ & $123(20.80)$ & 0.812 \\
\hline Other vitamin A-rich fruits and vegetables & $66(34.20)$ & $65(31.90)$ & $34(25.20)$ & $15(25.90)$ & $180(30.50)$ & 0.283 \\
\hline Other fruits & $160(82.90)$ & $168(82.40)$ & $102(75.60)$ & $33(56.90)$ & $463(78.50)$ & $<0.001$ \\
\hline Other oils and fats & $116(60.10)$ & $116(56.86)$ & $74(54.81)$ & $37(63.79)$ & $343(58.13)$ & 0.611 \\
\hline Savory and fried snacks & $15(7.77)$ & $13(6.37)$ & $14(10.37)$ & $5(8.62)$ & $47(7.97)$ & 0.612 \\
\hline Sweets & $129(66.84)$ & $162(79.41)$ & $99(73.33)$ & $49(84.48)$ & $439(74.41)$ & 0.009 \\
\hline Sugar-sweetened beverages & $164(84.97)$ & $180(88.23)$ & $121(89.63)$ & $52(89.66)$ & $517(87.62)$ & 0.564 \\
\hline Red meat and/or processed & $84(43.52)$ & $93(45.59)$ & $53(39.26)$ & $25(43.10)$ & $255(43.22)$ & 0.720 \\
\hline
\end{tabular}

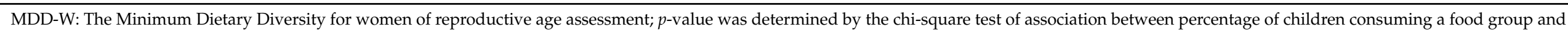
groups of daily frequency of eating at home. 
Crude and adjusted mean of MDD-W score according to groups of daily frequency of eating at home are presented in Table 3. Children who recorded $<2$ eating occasions at home $(\mathrm{G} 1=5.37,95 \% \mathrm{CI} 5.20 ; 5.55)$ and those who recorded $\geq 4(\mathrm{G} 4=4.74,95 \% \mathrm{CI} 0.16$; 4.42 ) presented the highest difference in MDD-W score ( $p$-value $=0.002)$. In multivariate analysis, G1 was characterized by a significantly higher MDD-W score compared to the other groups (G1 $=4.98,95 \%$ CI $4.46 ; 5.49 ; \mathrm{G} 2=4.48,95 \% \mathrm{CI} 4.35 ; 5.42 ; \mathrm{G} 3=4.75,95 \% \mathrm{CI}$ $4.20 ; 5.31$; and G4 $=4.24,95 \%$ CI 3.63; $4.84, p$-value $=0.005$ ). No statistically significant differences were observed in MDD-W score between G3 and the other groups.

Table 3. MDD-W score according to groups of daily eating at home frequency (mean values and $95 \%$ confidence intervals).

\begin{tabular}{cccccc}
\hline MDD-W Score & G1 & G2 & G3 & G4 & $p$-Value \\
\hline Crude & $5.37(5.20 ; 5.55) *$ & $5.36(5.19 ; 5.23) *$ & $5.10(4.89 ; 5.30)$ & $4.74(0.16 ; 4.42)$ & 0.002 \\
Adjusted & $4.98(4.46 ; 5.49) *$ & $4.88(4.35 ; 5.42) *$ & $4.75(4.20 ; 5.31)$ & $4.24(3.63 ; 4.84)$ & 0.005 \\
\hline
\end{tabular}

MDD-W: The Minimum Dietary Diversity for Women of reproductive age assessment; means adjusted to age, sex, atopy, self-reported medical diagnosis of FA, body mass index categories, parental education, child nutritional supplementation, number of eating occasions and total energy; *: Mean value was significantly different from that for Q4 $(<0.05)$.

In fully adjusted models (model 2), children who consumed at least 5 food groups had decreased odds of having increased levels of eNO (OR $=0.46,95 \%$ CI $0.24 ; 0.89$, $p$-value $=0.020$, Table 4$)$. No significant associations were found between the MDD-W indicator with positive bronchodilation or asthma definitions (Table 4). However, regarding respiratory symptoms in the previous 12 months, in adjusted models those with higher diet diversity consumption were more likely report coughs $(\mathrm{OR}=2.48,95 \% \mathrm{CI} 1.05 ; 5.87$, $p$-value $=0.038)$. No significant associations were found between diet diversity and lung function (Table S2).

Table 4. Association between increased levels of eNO, positive bronchodilation, asthma definitions, asthma symptoms in the previous 12 months and current respiratory symptoms in the previous 3 months with MDD-W indicator (odds ratio (OR) and 95\% confidence interval (CI)).

\begin{tabular}{|c|c|c|c|c|c|c|}
\hline Outcomes & Crude Model & $p$-Value & Model 1 & $p$-Value & Model 2 & $p$-Value \\
\hline Increased levels of eNO & $0.57(0.34 ; 0.96)$ & 0.035 & $0.46(0.24 ; 0.88)$ & 0.019 & $0.46(0.24 ; 0.89)$ & 0.020 \\
\hline$+\mathrm{BD}$ & $0.72(0.33 ; 1.56)$ & 0.723 & $0.57(0.24 ; 1.35)$ & 0.203 & $0.56(0.24 ; 1.33)$ & 0.562 \\
\hline \multicolumn{7}{|l|}{ Asthma definitions } \\
\hline Eve & $0.83(0.41 ; 1.68)$ & 0.832 & $1.16(0.44 ; 3.01)$ & 0.769 & $1.19(0.45 ; 3.13)$ & 0.727 \\
\hline Medical diagnosis with asthma symptoms or $+\mathrm{BD}$ & $0.95(0.50 ; 1.81)$ & 0.881 & $1.03(0.47 ; 2.22)$ & 0.950 & $1.02(0.47 ; 2.21)$ & 0.965 \\
\hline Medical diagnosis and under asthma treatment & $0.76(0.35 ; 1.63)$ & 0.478 & $1.17(0.41 ; 3.37)$ & 0.770 & $1.18(0.41 ; 3.41)$ & 0.761 \\
\hline \multicolumn{7}{|l|}{ Asthma symptoms } \\
\hline Wheezing & $1.07(0.54 ; 2.10)$ & 0.853 & $1.68(0.66 ; 4.26)$ & 0.275 & $1.68(0.66 ; 4.27)$ & 0.279 \\
\hline Cough & $1.12(0.62 ; 2.03)$ & 0.699 & $2.39(1.02 ; 5.60)$ & 0.046 & $2.48(1.05 ; 5.87)$ & 0.038 \\
\hline \multicolumn{7}{|l|}{ Current respiratory symptoms } \\
\hline Breathing difficulties & $0.76(0.41 ; 1.39)$ & 0.370 & $0.90(0.41 ; 1.96)$ & 0.792 & $0.89(0.41 ; 1.96)$ & 0.782 \\
\hline Irritative cough & $1.11(0.72 ; 1.71)$ & 0.631 & $1.57(0.91 ; 2.68)$ & 0.103 & $1.58(0.92 ; 2.71)$ & 0.098 \\
\hline
\end{tabular}

MDD-W: The Minimum Dietary Diversity for Women of reproductive age assessment. Increased levels of eNO: fractional exhaled nitric oxide levels $\geq 35 \mathrm{ppb} ;+\mathrm{BD}$ : positive bronchodilation defined by at least a $12 \%$ and over $200 \mathrm{~mL}$ increase in forced expiratory volume in $1 \mathrm{~s}$ (FEV1). Ever asthma: self-reported medical diagnosis; medical diagnosis or +BD: self-reported medical diagnosis or positive bronchodilation; medical diagnosis with asthma symptoms or +BD: self-reported medical diagnosis with reported symptoms (wheezing, dyspnea or dry cough) occurring in the past 12 months or positive bronchodilation; medical diagnosis and under asthma treatment: self-reported medical diagnosis and currently under anti-asthma medication; asthma symptoms: symptoms in the previous 12 months; current respiratory symptoms: symptoms in the previous 3 months; crude model: main effects; model 1: age, sex, atopy, self-reported medical diagnosis of FA, body mass index categories, parental education, maternal smoking during pregnancy, tobacco smoke at home, child nutritional supplementation, and groups of daily eating at home frequency; model 2: model 1, concerning food score and total energy intake.

\section{Discussion}

This cross-sectional study showed that children having less eating occasions at home had higher diet diversity compared to those who have more eating occasions at home. 
Furthermore, a greater diet diversity consumption was associated with lower eNO, as well as higher odds of having a cough in the previous year.

In our study, the location of each eating occasion was determined based on where the food was consumed. Although previous studies applied the same definition [22,25], others used different criteria, including the place where the meal was prepared [39,40]. This use of different definitions makes comparisons between studies difficult. Nevertheless, it was previously demonstrated that in children aged between 6 to 12 years, diet quality (measured through the Healthy Eating Index) was negatively associated with meals away from home, while no association was found with meals from school [39]. Similarly, among participants aged 11 to 18 years, the overall diet quality score was significantly higher among low and moderate consumers $(\mathrm{B}=2.8,95 \% \mathrm{CI} 1.0,4.6 \% ; p<0.01$ and $\mathrm{B}=3.4 \%, 95 \%$ CI 1.7, 5.0\%, $p<0.01$, respectively) compared with frequent consumers of meals out [41]. In addition, a study conducted in restaurants and shopping centers from Portugal found that children's menus often include nutritionally poor food and had low availability of vegetables and fruits [42].

Although the diet in Portugal is frequently associated with the Mediterranean pattern, results from national studies showed a high intake of fruits and vegetables but also a high consumption of energy-dense foods such as sugar sweetened beverages and snacks [43]. Nevertheless, the results from the present study showed that children consuming more meals at home had lower diet diversity, which was accompanied by a higher total energy and sweets intake. A possible explanation might be the fact that among the $68 \%$ of children who had meals at schools, $65 \%$ reported that they consumed at least half of their meals at school (data not shown), which might have positively impacted the diet diversity of those who consumed less meals at home. In accordance, results from the Portuguese birth cohort Generation XXI found that the mean dietary adequacy index was higher for children in the "pre-school" group $(18.3,95 \%$ CI 18.1, 18.4) when compared to other groups, including "home" (17.6, 95\% CI 17.1, 17.7, p< 0.001) [22]. In addition, Vepsäläinen et al., showed that schools from Portugal had more availability of healthy foods compared to empty-calorie foods [44]. It was also showed that there was a low household adherence to the Mediterranean dietary pattern in all Portuguese regions [45]. Results from the National Diet and Nutrition Survey Rolling Program, which included children aged 4 to 10 years, showed that the mean overall intake of fruits and vegetables was higher when meals were prepared at schools rather than prepared at home (66.2 \pm 2.5 vs. $59.3 \pm 2.8, p=0.06)$ [40].

Our results revealed a negative association between dietary diversity and increased levels of eNO. Although the role of dietary components on eNO levels has been previously assessed, the majority of published results come from studies conducted in patients with asthma. Nevertheless, it was shown that among children with asthma, the consumption of butter, which has high content of saturated fatty acids (SFA), was positively correlated with FeNO levels $(r=0.29, p=0.001)$ [46]. This correlation was negative for the consumption of salad ( $\mathrm{r}=-0.20, p=0.025)$ [46]. Similarly, results from a cross-sectional study of adult patients with asthma revealed a positive association between n-6:n-3 polyunsaturated fatty acids, and monounsaturated fatty acids: SFA ratio with eNO ( $\beta=0.05,95 \% \mathrm{CI} 0.02,0.09$ and $\beta=0.64,95 \%$ CI $0.08,1.20$, respectively) [47]. Children with moderate to severe asthma whose diet was supplemented with nutritional/dietary supplements (resveratrol, folic acid, magnesium, zinc, vitamin $\mathrm{D}$, among others, for 1 month), had significantly reduced FeNO levels (baseline $=19.0$ vs. after $=11.0, p=0.03$ ), while the non-supplemented group did not presented significant differences (18. vs. 16.0, $p=0.13$ ) [48].

On the other hand, there are studies showing no associations between dietary components and eNO levels. Chambers and Ayres showed that among healthy participants, the oral supplementation with ascorbic acid did not change the eNO levels [49]. In adults with allergies, there were no significant associations between the serum levels of antioxidant dietary compounds, such as vitamins C, E, b-carotene, and selenium, and eNO levels [49]. More recently, in a double-blind, placebo-controlled, randomized trial of 3 days, adult patients with asthma were assigned to the broccoli sprouts group, in which the intervention 
implicated the consumption of $100 \mathrm{~g}$ of broccoli sprouts daily or to the placebo group, which requires the consumption of $100 \mathrm{~g}$ of alfalfa sprouts, there were no significant reductions of eNO levels [50]. The difference in the results might be explained through the fact that an individuals' diet is composed of different dietary compounds that are consumed together and may exhibit synergic effects within and between foods [5]. In addition, the number of participants was low, which might compromise the power to detect significant differences. Altogether, these results highlight the importance of studying the entire diet to consider the complexity of food matrixes, as we did in the present study.

Endogenous NO is important in airway function regulation, being involved in respiratory diseases such as asthma [51]. The evaluation of eNO has been used to assess airway inflammation, and although it is correlated with eosinophilic airway inflammation, it is not present in all patients with asthma [52]. In fact, in the present study, among children with higher eNO $(n=75)$, only 18 have asthma defined by self-reported medical diagnosis with reported symptoms (wheezing, dyspnea, or dry cough) occurring in the past 12 months or positive bronchodilation (data not shown). Moreover, our group previously showed that eNO had very low diagnostic accuracy for asthma [53]. Nonetheless, the mechanisms that led its production, either to be a mediator of cell damage or a mechanism of defense under pro-oxidant environments, are not completely understood [46]. Cardinale et al., hypothesized that pro-oxidant environments with high levels of pro-inflammatory cytokines might increase the activity from the inducible NO synthase enzyme, which will protect the airways from oxidative stress damage [14]. Considering the previous hypothesis, it is also expected that a higher dietary diversity, with higher nutrient adequacy and dietary quality, will provide several dietary components with anti-oxidant and anti-inflammatory properties that might decrease the production of pro-inflammatory cytokines [12], consequently decreasing the NO production.

Contrarily to what we were expecting, the results from our study showed a positive association between diet diversity and cough in the previous 12 months. In fact, a systematic review concluded that higher adherence to the Mediterranean diet was negatively associated with asthma symptoms in children [15]. More recently, another systematic review emphasized a potential negative association between dietary diversity and wheeze and asthma [54]. A possible explanation might be the cross-sectional design of the study, in which these associations might have resulted from a reverse causation, where the consumption of dietary diversity was modified because of a previous diagnosis of allergic or respiratory condition. This study has a few limitations. Its cross-sectional design does not allow establishing causal relationships between dietary diversity consumption and the respiratory outcomes. However, it is unlikely that an inverse causal inference occurred, since we assessed important lifestyle variables which might be related with both diet and respiratory outcomes [55], including total energy intake, food allergy, atopy, and body mass categories that, together with other confounders, were taken into consideration in the association between diet diversity and respiratory outcomes. We collected a single $24 \mathrm{~h}$ recall questionnaire, although multiple recalls are better to report habitual intake [56]. In addition, it is designed to evaluate short-term intake and did not account for seasonality differences. Moreover, the reported intake in the previous $24 \mathrm{~h}$ might not represent a typical day. Nonetheless, $24 \mathrm{~h}$ recall questionnaires were collected by nutritionists and trained interviewers who applied photos and food models, which helped the children to quantify portion sizes without misreporting, avoiding influencing children's responses [57]. Furthermore, we collected detailed information about cooking methods, ingredients used in mixed dishes, brands of food and beverages consumed, and portion sizes. In this regard, the $24 \mathrm{~h}$ recall questionnaire seems to be useful to estimate children's current diet since it avoids the introduction of errors associated with memory and knowledge about food [58], even knowing that dietary data might be affected by a recall bias. Additionally, recalling the most recent foods and beverages consumed in the previous $24 \mathrm{~h}$ might be easier for children. Analyzing diet diversity consumption by groups organized by daily eating at home frequency just have to account for the number of meals consumed at home, 
which might influence the error of the association of certain food groups to specific eating occasions. However, groups allow comparison between groups with the highest and lowest number of eating occasions at home, being less sensitive to the effects of outliers than continuous variables [59]. Confounders were selected based on both knowledge of their relationship with diet and with the outcomes evaluated and evidence from previous literature, although residual confounding may still exist. Lastly, the generalization of the results should be performed with caution, considering that the research is restricted to Portugal. We also acknowledge some strengths to the present study. To our knowledge, this is the first study evaluating the MDD-W score among groups of daily eating at home frequency in school-aged children and its association with asthma and its related outcomes. Diet was classified according to MDD-W score, used to evaluate the overall diet diversity [33], and validated as a proxy measure for assessing micronutrient adequacy at the population-level [27]. In addition, this score was shown to be better for the characterization of seasonal variability and micronutrient adequacy among children between 4 to 8 years of age when compared to the 7-food group score [29]. We considered different respiratory outcomes and asthma definitions, including objective measures obtained from spirometry with bronchodilation and ISAAC self-reported responses [53]. Lastly, the data collected was detailed and performed by the same research team, allowing a relatively unbiased estimation of outcomes prevalence.

\section{Conclusions}

Our study showed that a higher diet diversity consumption was negatively associated with airway inflammation. In addition, having more eating episodes at home might be a possible barrier to better diet diversity. Strategies aimed to promote diets with more diversity of food groups, providing adequacy in micronutrients, should be prioritized.

Supplementary Materials: The following are available online at https:/ / www.mdpi.com/1660-460 1/18/5/2646/s1, Table S1: Characteristics of the participants included and non-included, Table S2: Association between lung function and MDD-W indicator ( $\beta$ and 95\% CI).

Author Contributions: Investigation, F.d.C.-M., P.C., I.P., J.C.R., J.C.R., M.F., and D.S.; Methodology, F.d.C.-M., P.C., A.M., and P.M.; Data curation, F.d.C.-M., P.C., I.P., J.C.R., M.F., and D.S., Conceptualization, A.M., and P.M., Formal analysis, F.d.C.-M., P.C., A.M, and P.M., Funding acquisition, A.M., Writing- Original draft preparation, F.d.C.-M., and P.M.; Writing- Review \& Editing, I.P., J.C.R., M.F., D.S., P.P., L.D., A.M., and P.M. All authors have read and agreed to the published version of the manuscript.

Funding: Authors gratefully acknowledge the funding by EXALAR 21 project financed by FEDER/ FNR and by Fundação para a Ciência e Tecnologia (EXALAR 21 02/SAICT/2017_Project n 30193). FCM kindly acknowledges the funding by Fundação para a Ciência e Tecnologia, through the scholarship SFRH/BD/144563/2019, as well as a Fulbright Research Grant from Fulbright Portugal.

Institutional Review Board Statement: The study was conducted according to the guidelines of the Declaration of Helsinki, and approved by the University Health Ethics Committee.

Informed Consent Statement: Written consent was obtained from children's legal guardians.

Data Availability Statement: The data presented in this study are available on reasonable request from the corresponding au-thor. The data are not publicly available due to ethical requirements.

Conflicts of Interest: The authors declare no conflict of interest.

\section{References}

1. Julia, V.; Macia, L.; Dombrowicz, D. The impact of diet on asthma and allergic diseases. Nat. Rev. Immunol. 2015, 15, 308-322. [CrossRef]

2. Wypych, T.P.; Marsland, B.J.; Ubags, N.D.J. The Impact of Diet on Immunity and Respiratory Diseases. Ann. Am. Thorac. Soc. 2017, 14 (Suppl. 5), S339-S347. [CrossRef]

3. Garcia-Larsen, V.; Del Giacco, S.R.; Moreira, A.; Bonini, M.; Charles, D.; Reeves, T.; Carlsen, K.-H.; Haahtela, T.; Bonini, S.; Fonseca, J.; et al. Asthma and dietary intake: An overview of systematic reviews. Allergy 2016, 71, 433-442. [CrossRef] 
4. Varraso, R. Nutrition and Asthma. Curr. Allergy Asthma Rep. 2012, 12, 201-210. [CrossRef]

5. Tapsell, L.C.; Neale, E.P.; Satija, A.; Hu, F.B. Foods, nutrients, and dietary patterns: Interconnections and implications for dietary guidelines. Adv. Nutr. 2016, 7, 445-454. [CrossRef] [PubMed]

6. Cunha, P.; Moreira, A.; Moreira, P.; Delgado, L. Dietary diversity and childhood asthma-Dietary acid load, an additional nutritional variable to consider. Allergy 2020, 75, 2418-2420. [CrossRef]

7. Arimond, M.; Ruel, M.T. Dietary Diversity Is Associated with Child Nutritional Status: Evidence from 11 Demographic and Health Surveys. J. Nutr. 2004, 134, 2579-2585. [CrossRef] [PubMed]

8. Drewnowski, A.; Henderson, S.A.; Shore, A.B.; Fischler, C.; Preziosi, P.; Hercberg, S. Diet quality and dietary diversity in France: Implications for the French paradox. J. Am. Diet. Assoc. 1996, 96, 663-669. [CrossRef]

9. Kennedy, E. Dietary diversity, diet quality, and body weight regulation. Nutr. Rev. 2004, 62, S78-S81. [CrossRef]

10. Burggraf, C.; Teuber, R.; Brosig, S.; Meier, T. Review of a priori dietary quality indices in relation to their construction criteria. Nutr. Rev. 2018, 76, 747-764. [CrossRef]

11. Cunha, P.; Paciência, I.; Cavaleiro Rufo, J.; Castro Mendes, F.; Farraia, M.; Barros, R.; Silva, D.; Delgado, L.; Padrão, P.; Moreira, A.; et al. Dietary Acid Load: A Novel Nutritional Target in Overweight/Obese Children with Asthma? Nutrients 2019, 11, 2255. [CrossRef]

12. Guilleminault, L.; Williams, E.J.; Scott, H.A.; Berthon, B.S.; Jensen, M.; Wood, L.G. Diet and Asthma: Is It Time to Adapt Our Message? Nutrients 2017, 9, 1227. [CrossRef] [PubMed]

13. Arvaniti, F.; Priftis, K.N.; Papadimitriou, A.; Papadopoulos, M.; Roma, E.; Kapsokefalou, M.; Anthracopoulos, M.B.; Panagiotakos, D.B. Adherence to the Mediterranean type of diet is associated with lower prevalence of asthma symptoms, among 10-12 years old children: The PANACEA study. Pediatric Allergy Immunol. 2011, 22, 283-289. [CrossRef] [PubMed]

14. Castro-Rodriguez, J.A.; Garcia-Marcos, L. What Are the Effects of a Mediterranean Diet on Allergies and Asthma in Children? Front. Pediatrics 2017, 5, 72. [CrossRef]

15. Papamichael, M.M.; Itsiopoulos, C.; Susanto, N.H.; Erbas, B. Does adherence to the Mediterranean dietary pattern reduce asthma symptoms in children? A systematic review of observational studies. Public Health Nutr. 2017, 20, 2722-2734. [CrossRef]

16. Barros, R.; Moreira, A.; Fonseca, J.; Ferraz de Oliveira, J.; Delgado, L.; Castel-Branco, M.G.; Haahtela, T.; Lopes, C.; Moreira, P. Adherence to the Mediterranean diet and fresh fruit intake are associated with improved asthma control. Allergy 2008, 63, 917-923. [CrossRef] [PubMed]

17. Andrianasolo, R.M.; Kesse-Guyot, E.; Adjibade, M.; Hercberg, S.; Galan, P.; Varraso, R. Associations between dietary scores with asthma symptoms and asthma control in adults. Eur. Respir. J. 2018, 52, 1702572. [CrossRef]

18. Li, Z.; Kesse-Guyot, E.; Dumas, O.; Garcia-Aymerich, J.; Leynaert, B.; Pison, C.; Le Moual, N.; Romieu, I.; Siroux, V.; Camargo, C.A.; et al. Longitudinal study of diet quality and change in asthma symptoms in adults, according to smoking status. Br. J. Nutr. 2017, 117, 562-571. [CrossRef] [PubMed]

19. Tarazona-Meza, C.E.; Hanson, C.; Pollard, S.L.; Romero Rivero, K.M.; Galvez Davila, R.M.; Talegawkar, S.; Rojas, C.; Rice, J.L.; Checkley, W.; Hansel, N.N. Dietary patterns and asthma among Peruvian children and adolescents. BMC Pulm. Med. 2020, 20, 63. [CrossRef]

20. Lachat, C.; Nago, E.; Verstraeten, R.; Roberfroid, D.; Van Camp, J.; Kolsteren, P. Eating out of home and its association with dietary intake: A systematic review of the evidence. Obes. Rev. 2012, 13, 329-346. [CrossRef]

21. Goffe, L.; Rushton, S.; White, M.; Adamson, A.; Adams, J. Relationship between mean daily energy intake and frequency of consumption of out-of-home meals in the UK National Diet and Nutrition Survey. Int. J. Behav. Nutr. Phys. Act. 2017, 14, 131. [CrossRef] [PubMed]

22. Moreira, T.; Severo, M.; Oliveira, A.; Ramos, E.; Rodrigues, S.; Lopes, C. Eating out of home and dietary adequacy in preschool children. Br. J. Nutr. 2015, 114, 297-305. [CrossRef] [PubMed]

23. Au, L.E.; Rosen, N.J.; Fenton, K.; Hecht, K.; Ritchie, L.D. Eating School Lunch Is Associated with Higher Diet Quality among Elementary School Students. J. Acad. Nutr. Diet. 2016, 116, 1817-1824. [CrossRef] [PubMed]

24. Kinderknecht, K.; Harris, C.; Jones-Smith, J. Association of the Healthy, Hunger-Free Kids Act with Dietary Quality Among Children in the US National School Lunch Program. JAMA 2020, 324, 359-368. [CrossRef]

25. Andrade, G.C.; Gombi-Vaca, M.F.; da Costa Louzada, M.L.; Azeredo, C.M.; Levy, R.B. The consumption of ultra-processed foods according to eating out occasions. Public Health Nutr. 2020, 23, 1041-1048. [CrossRef] [PubMed]

26. Onita, B.M.; Azeredo, C.M.; Jaime, P.C.; Levy, R.B.; Rauber, F.J.A. Eating context and its association with ultra-processed food consumption by British children. Appetite 2020, 157, 105007. [CrossRef]

27. Women's Dietary Diversity Project (WDDP) Study Group. Development of a Dichotomous Indicator for Population-Level Assessment of Dietary Diversity in Women of Reproductive Age. Curr. Dev. Nutr. 2017, 1. [CrossRef]

28. Fung, T.T.; Isanaka, S.; Hu, F.B.; Willett, W.C. International food group-based diet quality and risk of coronary heart disease in men and women. Am. J. Clin. Nutr. 2018, 107, 120-129. [CrossRef] [PubMed]

29. Caswell, B.L.; Talegawkar, S.A.; Siamusantu, W.; West, K.P., Jr.; Palmer, A.C. A 10-Food Group Dietary Diversity Score Outperforms a 7-Food Group Score in Characterizing Seasonal Variability and Micronutrient Adequacy in Rural Zambian Children. J. Nutr. 2018, 148, 131-139. [CrossRef] 
30. Paciência, I.; Cavaleiro Rufo, J.; Silva, D.; Martins, C.; Mendes, F.; Farraia, M.; Delgado, L.; de Oliveira Fernandes, E.; Padrão, P.; Moreira, P.; et al. Exposure to indoor endocrine-disrupting chemicals and childhood asthma and obesity. Allergy 2019, 74, 1277-1291. [CrossRef]

31. Walker, J.L.; Ardouin, S.; Burrows, T. The validity of dietary assessment methods to accurately measure energy intake in children and adolescents who are overweight or obese: A systematic review. Eur. J. Clin. Nutr. 2018, 72, 185-197. [CrossRef] [PubMed]

32. Leech, R.M.; Worsley, A.; Timperio, A.; McNaughton, S.A. Understanding meal patterns: Definitions, methodology and impact on nutrient intake and diet quality. Nutr. Res. Rev. 2015, 28,1-21. [CrossRef]

33. FAO. Minimum Dietary Diversity for Women: A Guide for Measurement; FAO: Rome, Italy, 2016; Volume 82.

34. Asher, M.I.; Keil, U.; Anderson, H.R.; Beasley, R.; Crane, J.; Martinez, F.; Mitchell, E.A.; Pearce, N.; Sibbald, B.; Stewart, A.W.; et al. International Study of Asthma and Allergies in Childhood (ISAAC): Rationale and methods. Eur. Respir. J. 1995, 8, 483-491. [CrossRef]

35. Miller, M.R.; Hankinson, J.; Brusasco, V.; Burgos, F.; Casaburi, R.; Coates, A.; Crapo, R.; Enright, P.; van der Grinten, C.P.M.; Gustafsson, P.; et al. Standardisation of spirometry. Eur. Respir. J. 2005, 26, 319-338. [CrossRef] [PubMed]

36. De Castro Mendes, F.; Paciência, I.; Rufo, J.C.; Silva, D.; Cunha, P.; Farraia, M.; Delgado, L.; Moreira, P.; Moreira, A. Asthma and body mass definitions affect estimates of association: Evidence from a community-based cross-sectional survey. ERJ Open Res. 2019, 5, 00076-02019. [CrossRef]

37. Dweik, R.A.; Boggs, P.B.; Erzurum, S.C.; Irvin, C.G.; Leigh, M.W.; Lundberg, J.O.; Olin, A.C.; Plummer, A.L.; Taylor, D.R. An official ATS clinical practice guideline: Interpretation of exhaled nitric oxide levels (FENO) for clinical applications. Am. J. Respir. Crit. Care Med. 2011, 184, 602-615. [CrossRef]

38. Kuczmarski, R.J.; Ogden, C.L.; Grummer-Strawn, L.M.; Flegal, K.M.; Guo, S.S.; Wei, R.; Johnson, C.J.H. CDC Growth Charts: United States Advance Data from Vital and Health Statistics; No. 314; National Center for Health Statistics: Hyattsville, MD, USA, 2000.

39. Mancino, L.; Todd, J.E.; Guthrie, J.F.; Lin, B.-H. How Food Away from Home Affects Children's Diet Quality; USDA: Washington, DC, USA, 2010.

40. Ziauddeen, N.; Page, P.; Penney, T.L.; Nicholson, S.; Kirk, S.F.; Almiron-Roig, E. Eating at food outlets and leisure places and “on the go" is associated with less-healthy food choices than eating at home and in school in children: Cross-sectional data from the UK National Diet and Nutrition Survey Rolling Program (2008-2014). Am. J. Clin. Nutr. 2018, 107, 992-1003. [CrossRef] [PubMed]

41. Taher, A.K.; Evans, N.; Evans, C.E.L. The cross-sectional relationships between consumption of takeaway food, eating meals outside the home and diet quality in British adolescents. Public Health Nutr. 2019, 22, 63-73. [CrossRef]

42. Viegas, C.; Afonso, C.; Lima, J.P.; Mateus, M.P.; Rocha, A. Oferta alimentar de menus infantis em restaurantes de centros comerciais portugueses: Estudo qualitativo. J. Acta Port. Nutr. 2020, 21, 10-14. [CrossRef]

43. Pereira-da-Silva, L.; Rêgo, C.; Pietrobelli, A. The Diet of Preschool Children in the Mediterranean Countries of the European Union: A Systematic Review. Int. J. Environ. Res. Public Health 2016, 13, 572. [CrossRef]

44. Vepsäläinen, H.; Mikkilä, V.; Erkkola, M.; Broyles, S.T.; Chaput, J.P.; Hu, G.; Kuriyan, R.; Kurpad, A.; Lambert, E.V.; Maher, C.; et al. Association between home and school food environments and dietary patterns among 9-11-year-old children in 12 countries. Int. J. Obes. Suppl. 2015, 5, S66-S73. [CrossRef]

45. Rodrigues, S.S.P.; Caraher, M.; Trichopoulou, A.; de Almeida, M.D.V. Portuguese households' diet quality (adherence to Mediterranean food pattern and compliance with WHO population dietary goals): Trends, regional disparities and socioeconomic determinants. Eur. J. Clin. Nutr. 2008, 62, 1263-1272. [CrossRef]

46. Cardinale, F.; Tesse, R.; Fucilli, C.; Loffredo, M.S.; Iacoviello, G.; Chinellato, I.; Armenio, L. Correlation between exhaled nitric oxide and dietary consumption of fats and antioxidants in children with asthma. J. Allergy Clin. Immunol. 2007, 119, 1268-1270. [CrossRef]

47. Barros, R.; Moreira, A.; Fonseca, J.; Delgado, L.; Graça Castel-Branco, M.; Haahtela, T.; Lopes, C.; Moreira, P. Dietary intake of $\alpha$-linolenic acid and low ratio of n-6:n-3 PUFA are associated with decreased exhaled NO and improved asthma control. Br. J. Nutr. 2011, 106, 441-450. [CrossRef]

48. Tenero, L.; Piazza, M.; Zanoni, L.; Bodini, A.; Peroni, D.; Piacentini, G.L. Antioxidant supplementation and exhaled nitric oxide in children with asthma. Allergy Asthma Proc. 2016, 37, e8-e13. [CrossRef] [PubMed]

49. Chambers, D.C.; Ayres, J.G. Effects of nitrogen dioxide exposure and ascorbic acid supplementation on exhaled nitric oxide in healthy human subjects. Thorax 2001, 56, 774-778. [CrossRef]

50. Sudini, K.; Diette, G.B.; Breysse, P.N.; McCormack, M.C.; Bull, D.; Biswal, S.; Zhai, S.; Brereton, N.; Peng, R.D.; Matsui, E.C. A Randomized Controlled Trial of the Effect of Broccoli Sprouts on Antioxidant Gene Expression and Airway Inflammation in Asthmatics. J. Allergy Clin. Immunol. Pract. 2016, 4, 932-940. [CrossRef]

51. Ricciardolo, F.L.; Di Stefano, A.; Sabatini, F.; Folkerts, G. Reactive nitrogen species in the respiratory tract. Eur. J. Pharmacol. 2006, 533, 240-252. [CrossRef] [PubMed]

52. Nagase, H. The role of fractional nitric oxide in exhaled breath (FeNO) in clinical practice of asthma. Rinsho Byori Jpn. J. Clin. Pathol. 2014, 62, 1226-1233.

53. Silva, D.; Severo, M.; Paciência, I.; Rufo, J.; Martins, C.; Moreira, P.; Padrão, P.; Delgado, L.; Moreira, A. Setting definitions of childhood asthma in epidemiologic studies. Pediatric Allergy Immunol. Off. Publ. Eur. Soc. Pediatric Allergy Immunol. 2019, 30 , 708-715. [CrossRef] 
54. Venter, C.; Greenhawt, M.; Meyer, R.W.; Agostoni, C.; Reese, I.; du Toit, G.; Feeney, M.; Maslin, K.; Nwaru, B.I.; Roduit, C.; et al. EAACI position paper on diet diversity in pregnancy, infancy and childhood: Novel concepts and implications for studies in allergy and asthma. Allergy 2020, 75, 497-523. [CrossRef] [PubMed]

55. Wright, C.Y.; Nkosi, V.; Wichmann, J. Respiratory Health Symptoms among Schoolchildren in Relation to Possible Food-Related Risk and Protective Factors. Int. J. Environ. Res. Public Health 2018, 15, 502. [CrossRef] [PubMed]

56. Shim, J.-S.; Oh, K.; Kim, H.C. Dietary assessment methods in epidemiologic studies. Epidemiol. Health 2014, 36, e2014009. [CrossRef]

57. Biró, G.; Hulshof, K.F.; Ovesen, L.; Amorim Cruz, J.A. Selection of methodology to assess food intake. Eur. J. Clin. Nutr. 2002, 56 (Suppl. 2), S25-S32.

58. Ortega, R.M.; Pérez-Rodrigo, C.; López-Sobaler, A.M. Dietary assessment methods: Dietary records. Nutr. Hosp. 2015, 31 (Suppl. 3), 38-45. [PubMed]

59. Mattioli, V.; Zanolin, M.E.; Cazzoletti, L.; Bono, R.; Cerveri, I.; Ferrari, M.; Pirina, P.; Garcia-Larsen, V. Dietary flavonoids and respiratory diseases: A population-based multi-case-control study in Italian adults. Public Health Nutr. 2020, 23, $2548-2556$. [CrossRef] [PubMed] 